\title{
3D Numerical Modelling of Tailings Dam Breach Run Out Flow over Complex Terrain: A Multidisciplinary Procedure
}

\author{
Kun Wang ${ }^{1} \mathbb{D}$, Peng Yang ${ }^{2, *}$, Guangming $\mathrm{Yu}^{3}$, Chao Yang ${ }^{4}$ and Liyi Zhu ${ }^{4}$ \\ 1 College of Energy and Mining Engineering, Shandong University of Science and Technology, \\ Qingdao 266590, China; kwang@sdust.edu.cn \\ 2 Beijing Key Laboratory of Information Service Engineering, Beijing Union University, Beijing 100101, China \\ 3 School of Civil Engineering, Qingdao University of Technology, Qingdao 266033, China; \\ yu-guangming@263.net \\ 4 School Civil and Resource Engineering, University of Science and Technology Beijing, Beijing 100083, China; \\ yang0chao199065@163.com (C.Y.); zly0095@126.com (L.Z.) \\ * Correspondence: yangpeng@buu.edu.cn
}

Received: 6 August 2020; Accepted: 7 September 2020; Published: 11 September 2020

\begin{abstract}
Tailings dams, as essential mining structures, are being built globally for containing the chief waste stream of the mining industry. Catastrophic tailings dam breaches have occurred frequently over the past decade, causing severe impacts on the environment, economy, and human health. The foreknowledge of the tailings dam breach overland flow is crucial for the risk assessment and emergency response planning in order to prevent or minimize possible losses. Using unmanned aerial vehicles (UAV) photogrammetry and smoothed particle hydrodynamics (SPH) numerical method, this study proposed a multidisciplinary procedure for modelling a hypothetical tailings dam breach run out flow over the downstream complex terrain. A case study on a 97-m-height tailings dam in Shandong Province of China was carried out. The proposed procedure was proven applicable to determine the overland tailings flow. The submerged area and flow velocities suggested that the downstream G2 highway would hardly be threatened and more concerns should be paid on the factory plants and workers deployed between the dam toe and the highway. Additionally, the application of UAV photogrammetry in the mining industry as a supplementary surveying method can be further expanded, especially for the numerous small-scale mining sites. The proposed procedure is then recommended for the safety management of the tailings' storage facilities globally.
\end{abstract}

Keywords: tailings storage facility; tailings dam breach; unmanned aerial vehicles; smoothed particle hydrodynamics; photogrammetry

\section{Introduction}

A tailings storage facility (TSF) is an essential structure in the mining industry built for the purpose of storing unwanted and currently uneconomical mine waste tailings behind one or more tailings dams. Unlike water-retaining dams, where construction materials usually consist of concrete, rock, or soil, tailings dams are mostly being built using tailings themselves in order to minimize costs [1]. Therefore, the operation and emergency management are often more complicated in terms of higher risks of dam breach, debris flow, or overtopping accidents. The literatures [2,3] present that the rate of tailings dam breach (TDB) accident over the 100 years between 1910 and 2010 was estimated to be $1.2 \%$, which is more than two orders of magnitude higher than that of normal water-retaining dams $(0.01 \%)$. In the last two decades, with the great improvements in damming practices, regulation, and modern construction technology, the TDB accident rate has sufficiently 
decreased globally. Nevertheless, major TDB accidents with a sheer volume of released tailings or heavy casualties have been occurring more frequently [4,5]. For example [4], the Brumadinho dam accident at Córrego de Feijão iron ore mine in Minas Gerais, Brazil, occurred on 25 January 2019 and released almost its complete holdings of 12 million $\mathrm{m}^{3}$ of tailings. The mining loading station, administration buildings, and a railway branch downstream were submerged and destroyed by the devastating run out tailings flow. More than 249 people were killed. Only about three years earlier of the Brumadinho dam accident, on 5 November 2015, another catastrophic TDB accident occurred in Minas Gerais, Brazil. The Fundão tailings dam of Samarco iron mine collapsed and released 32 million $\mathrm{m}^{3}$ of tailings. The downstream community of Bento Rodriguez was flooded and 158 homes were destroyed. At least 17 people lost their lives and more than $650 \mathrm{~km}$ of rivers were contaminated.

The actions taken before or in the initial minutes of an unexpected accident are crucial, especially for the TDB accidents that initiate in very short time, release large volume of materials, transport in high velocities, and travel long distances. The foreknowledge of the run out overland flow (ROOF) can provide evidence for the administrators to develop and implement a more effective and reasonable emergency response plan. The on-site experiment is nearly impossible due to its uncontrollable and devastating process. The numerical method is considered to be an irreplaceable tool in modelling TDB problems in terms of its high efficiency, flexible settings, and reasonable costs. However, traditional grid methods such as the Finite Difference Method (FDM) and the Finite Element Method (FEM) can lead to inevitable numerical difficulties including mesh winding, twisting, and distortion in modelling problems with large deformation and free surfaces [6,7]. The fully mesh-free, particle-based Lagrangian method of Smoothed Particle Hydrodynamics (SPH) proposed by Lucy [8], Gingold and Monaghan [9] is becoming more commonly used in the latest geo-disaster studies [6,10]. For example, Huang et al. [11] analyzed the flow-like landsides triggered by an earthquake in China with the SPH method and the results indicated good agreement with observed field characteristics. Pastor et al. [12] used depth-integrated $\mathrm{SPH}$ models incorporating pore pressure dissipation to simulate the propagation phase of typical landslides and believed that the computational time could be reduced up to 30 times when compared with mesh methods. Vacondio et al. [13] adopted SPH to simulate falling slide-generated flow in a water reservoir. The flow maximum run-up distances and surface elevations were reproduced satisfactorily. Manenti et al. [14] introduced some engineering applications of the SPH method in modelling the two-phase coupled dynamics such as fast landslides and flooding hazards. McDougall and Hungr [15] developed an SPH-adapted numerical model to analyze rapid landside motion across 3D terrain and designed a series of laboratory flume tests for verification. On the other hand, the run-out flow properties such as velocities, submerged depths, and directions can be directly affected by the complex terrains. However, to the best of the authors' knowledge, the downstream terrain was mostly simplified, ignored, or outdated in the previous studies, as the mining area is changing rapidly during the ore extracting and tailings' depositing processes. In our previous study [16], the procedure of integrating spaceborne remote sensing digital surface models (DSM) and the SPH method was proposed to predict the run out routings of tailings dam breach over downstream terrain. A laboratory flume experiment proved the applicability of the SPH method when modelling tailings slurry flow motions and the known 2015 Brazil Fundão dam breach accident. In the present study, the resolution and timeliness of the adopted DSM data will be improved by introducing the unmanned aerial vehicle (UAV) photogrammetry technique.

Therefore, the aim of this study is to determine the potential for using the UAV photogrammetry technique and the SPH numerical method to predict a hypothetical TDB run out flow over downstream real terrain. The proposed multidisciplinary procedure is shown in Figure 1. 


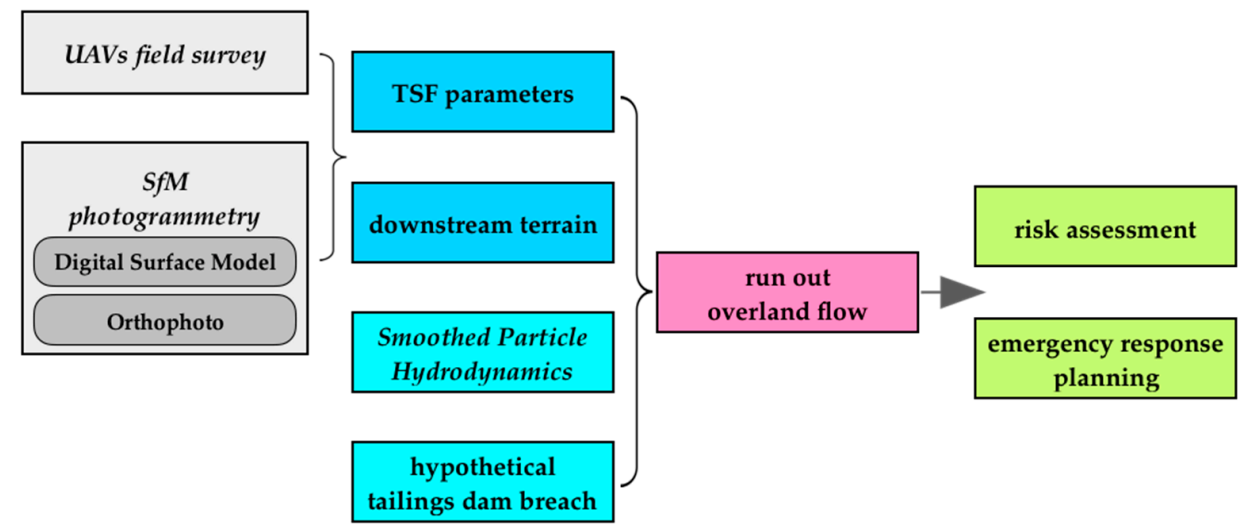

Figure 1. Flowchart of the proposed procedure for modelling the run-out flow of tailings dam breach.

\section{Materials and Methods}

\subsection{Study Area and Proposed Procedure}

The study site of the Yujiaquan TSF is situated in Laiwu city, Shandong Province of Eastern China, as Figure 2 shows. The TSF has been operating since 1985 in order to store mining waste from the Luzhong iron mine. It was designed to deposit tailings behind a 29-m-high compacted rockfill starter dam (El. $+256 \mathrm{~m} \sim$ El $+285 \mathrm{~m}$ ) and then augment capacity by upstream raising the main dam with the slope ratio of $1 / 4$. The annual disposal of tailings is estimated to be 2.6 million tons, which rises the TSF reservoir surface by $2.4 \mathrm{~m}$ every year. To ensure a safe and sustainable tailings disposal operation, the mining waste rocks, the relatively coarse tailings from the hydrocyclone underflow, and the permeable geotextile are utilized for the dam construction, as Figure 3 shows. The fine-grained hydrocyclone overflow slurry is then discharged into the TSF. The TSF designed maximum capacity was $52.55 \mathrm{Mm}^{3}$ with the dam height of $114 \mathrm{~m}$ (El. $370 \mathrm{~m}$ ). It can also be seen in Figure 2 that a densely populated community with more than 1000 residents is located only $1.2 \mathrm{~km}$ downstream of the TSF. In addition, the G2 highway, which links the capital city Beijing in Northern China and the central major city Shanghai, is crossing through the study area from the northwest to the southeast, which is approximately $1 \mathrm{~km}$ from the dam toe. Several factory plants and a water recovery pond are deployed on the flat area between the dam toe and the G2 highway.

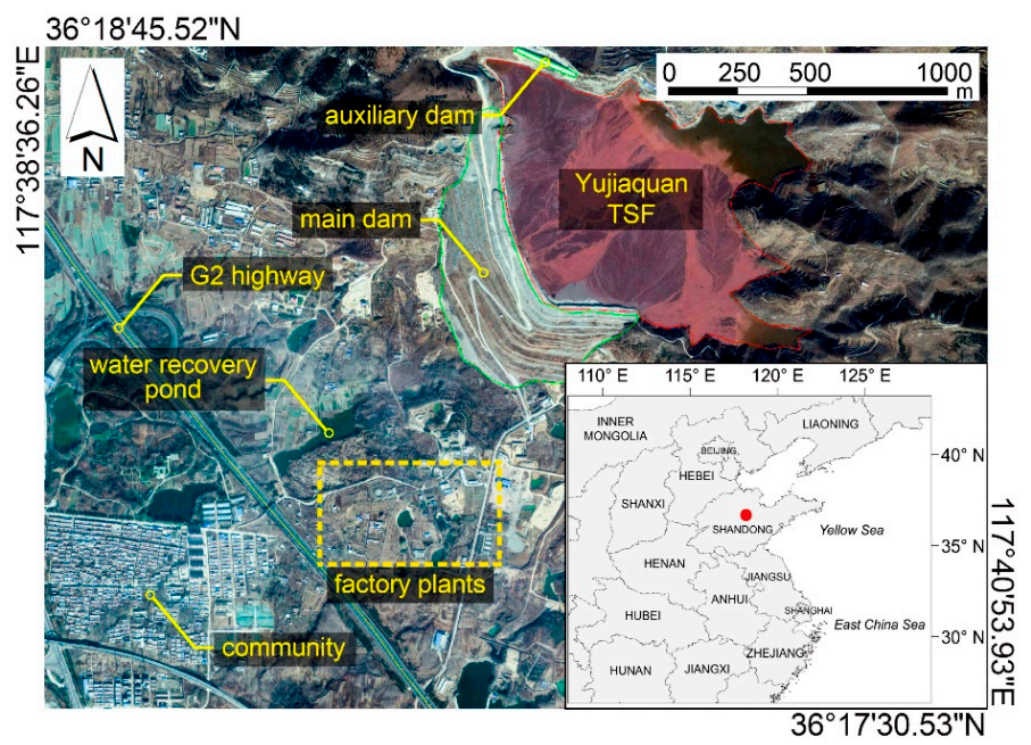

Figure 2. Aerial image of the research area, its location in China (insert), Yujiaquan tailings storage facility (TSF), and the downstream important facilities. 


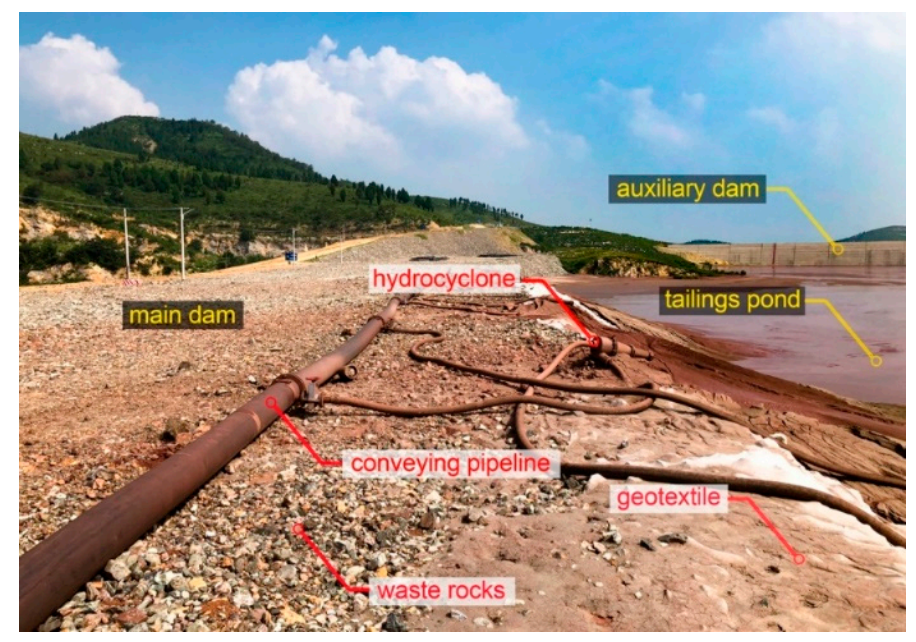

Figure 3. Upstream raising of the Yujiaquan main dam with tailings, waste rocks, geotextile, and hydro-cyclones.

\subsection{UAVs SfM-Photogrammetry and Field Surveys}

UAVs have recently been used for the surveillance of heritage, vegetation, landslides, and infrastructure engineering [17-21]. In addition to UAV technology, structure from motion (SfM) photogrammetry is a low-cost topographical survey technique for estimating three-dimensional structures from a two-dimensional image sequence. The SfM technique is described in detail by Westoby et al. [22]. Recent advances in photogrammetry software, high-performance computing, and consumer-grade UAVs have made SfM photogrammetry a reliable topographic survey technique in terms of reasonable costs, great flexibility, and efficiency. UAVs photogrammetry has become a matter of growing interest among both researchers and industries. Rauhala et al. [23] had successfully adopted the technique for the surveillance of a closed TSF in a subarctic area in Finland. The obtained results indicated that UAVs remote sensing can produce sufficiently accurate data for supporting tailings management operations and tracking annual surface displacements in the decimeter range. Barreiro et al. [24] applied UAV photogrammetry and the SPH method to compute the trajectory of the water flow across a close road during extreme weather events under different protection scenarios.

In the present study, the photogrammetric field surveys were performed in four stages: (1) mission planning, (2) acquisition of ground control points (GCPs), (3) flights implementation and images acquisition, and (4) photogrammetry processing. The aerial inspection devices used in this work were two four-propeller UAV drones from DJI (DJI, Shenzhen, China). One was the Phantom 4 Advanced model equipped with a digital FC6310 camera (1-inch 20-megapixel CMOS sensor, 24-mm f/2.8 wide-angle lens). The other one was the Phantom 3 Professional model equipped with a digital FC300X camera (1/2.3-inch 12-megapixel sensor, $20-\mathrm{mm} \mathrm{f} / 2.8$ wide-angle lens). The field images acquisition was performed on 1 August 2018. The sky condition was generally clear. As shown in Figure 4a,b, the UAVs were deployed on site. During the flights, the UAVs were controlled autonomously using the Pix4Dcapture mobile application (Pix4D, Prilly, Switzerland). The flying height was $100 \mathrm{~m}$ with the frontal overlap of $75 \%$ and side overlap of $60 \%$. The GCPs distributed evenly on the main dam crest and the dam body were recorded with a Hi-Target V30 GNSS RTK receiver (Hi-Target Surveying Instrument, Guangzhou, China) and several self-made GCP mark boards, as Figure 4c,d shows. The static positioning accuracy of $2.5 \mathrm{~mm}$ and the elevation accuracy of $5 \mathrm{~mm}$ can be achieved. Eventually, 3002 images and 33 GCPs data covering the $2.28 \mathrm{~km}^{2}$ study area were collected. The key features of UAV photogrammetry data acquisition are shown in Table 1. The photogrammetry processing was then performed on the high-performance cluster with 69 GB RAM and Intel ${ }^{\circledR}$ Xeon ${ }^{\circledR}$ Platinum 8124M CPU (Intel Corporation, Santa Clara, CA, USA) at $3.00 \mathrm{GHz}$. 
Table 1. Unmanned aerial vehicle (UAV) photogrammetry data acquisition of the study site.

\begin{tabular}{ccccccc}
\hline Date & Images & $\begin{array}{c}\text { Flight } \\
\text { Height }(\mathbf{m})\end{array}$ & $\begin{array}{c}\text { Area } \\
\left(\mathbf{k m}^{\mathbf{2}}\right)\end{array}$ & $\begin{array}{c}\text { Frontal } \\
\text { Overlap (\%) }\end{array}$ & $\begin{array}{c}\text { Side } \\
\text { Overlap (\%) }\end{array}$ & $\begin{array}{c}\text { Ground Control } \\
\text { Points (GCPs) }\end{array}$ \\
\hline 1 August 2018 & 3002 & 100 & 2.28 & $>75$ & $>60$ & 33 \\
\hline
\end{tabular}

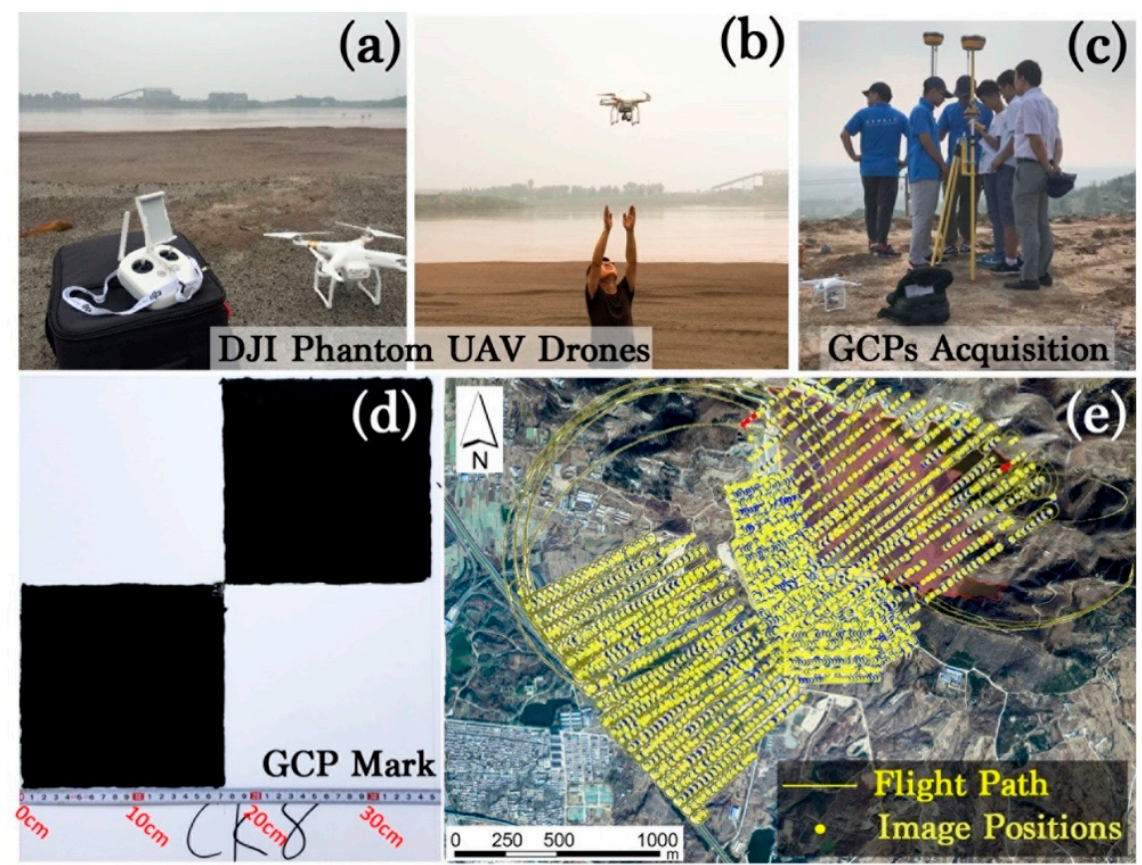

Figure 4. Photogrammetry data acquisition: $(\mathbf{a}, \mathbf{b})$ the DJI Phantom unmanned aerial vehicle (UAV) drones and field surveys, (c,d) ground control points (GCPs) acquisition, (e) flights implementation and images acquisition.

\subsection{Smoothed Particle Hydrodynamics (SPH) Method}

In $\mathrm{SPH}$, the continuum is represented by defining a set of discrete particles, rather than by generating mesh in traditional grid methods. Each particle is initially characterized by its specific physical properties such as mass, density, pressure, and energy. Then a particle is influenced by its neighboring particles by using the kernel approximation. The interpolation function designated as the smoothing kernel function can be written in a continuous form as:

$$
F(\mathbf{r}) \cong \int_{\Omega} F\left(\mathbf{r}^{\prime}\right) W\left(\mathbf{r}-\mathbf{r}^{\prime}, h\right) d \mathbf{r}^{\prime}
$$

where $h$ is the smoothing length, which indicates the interaction distance between two neighboring particles, $\mathbf{r}$ represents the particle location vector, $\Omega$ is the total supporting domain determined by $h$, and $W\left(\mathbf{r}-\mathbf{r}^{\prime}, h\right)$ is the Dirac delta weighting function, which is fundamental to the SPH approach.

Equation (1) can be expressed in a non-continuous form after a discrete approximation step as:

$$
F(\mathbf{r}) \approx \sum_{b}^{N} F\left(\mathbf{r}_{b}\right) \frac{m_{b}}{\rho_{b}} W\left(\mathbf{r}_{a}-\mathbf{r}_{\boldsymbol{b}}, h\right)
$$

where $N$ is the amount of neighboring particles, $m$ is the mass, and $\rho$ is the density. The smoothing function $W\left(\mathbf{r}_{a}-\mathbf{r}_{b}, h\right)$ is correlated with smoothing length $h$ and $\left(\mathbf{r}_{a}-\mathbf{r}_{b}\right)$, i.e., the distance between particles $a$ and $b$. In this study, the fifth-order quantic kernel by Wendland [25] where the weighting 
function vanishes for inter-particle distances greater than $2 h$ is used. The Wendland kernel is defined in 3D as:

$$
W\left(\mathbf{r}_{a}-\mathbf{r}_{b}, h\right)=\alpha_{D}(2 q+1)\left(1-\frac{q}{2}\right)^{4} 0 \leq q \leq 2
$$

where $q=\left(\mathbf{r}_{a}-\mathbf{r}_{b}\right) / h$ and $\alpha_{\mathrm{D}}$ is the normalization constant that equals to $7 /\left(4 \pi h^{2}\right)$ in $2 \mathrm{D}$ and $21 /\left(16 \pi h^{3}\right)$ in 3D.

To simplify the calculation of the pressure term, the weakly compressible state equation proposed by Monaghan [26] is adopted in this study. The equation, which relates the hydrostatic pressure to local densities, is as follows:

$$
P=B\left[\left(\frac{\rho}{\rho_{0}}\right)^{\lambda}-1\right]
$$

where constant $B$ sets a limit for the range of density values. $B$ equals to $200\left(\rho_{0}\right) g H / \gamma$ when the liquid level is $H$. Constant $\gamma$ is usually taken as 7 and $\rho_{0}$ is the reference density.

The momentum equation in the Lagrange coordinate system can be written as:

$$
\frac{d \mathbf{v}}{d t}=-\frac{1}{\rho} \nabla P+\mathbf{g}+\boldsymbol{\psi}
$$

where $P$ represents the pressure, $\mathbf{g}=(0,0,-9.81) \mathrm{m} / \mathrm{s}^{2}$ is the gravity acceleration, and $\psi$ is the dissipative term.

In most reported tailings dam breach cases and studies [27-29], the run out tailings flow is normally considered to be the homogeneous mud-water mixture similarly to debris flow at a low concentration of less than $40 \%$. In addition, its rheological behavior is often described as homogeneous non-Newtonian fluid [29-31]. The generalized Herschel-Bulkley-Papanastasiou (HBP) model proposed by Papanastasiou [32] is adopted in this study. The effective viscosity $\left(\mu_{e f f}\right)$ can be defined as:

$$
\mu_{e f f}=K(\gamma)^{n-1}+\frac{\tau_{y}}{2 \gamma}\left(1-e^{-2 m \gamma}\right)
$$

where $K$ and $m$ are the constant coefficients, $\dot{y}$ is the shear rate and $\tau_{y}$ is the yield stress. When $n=1$, the HBP model reduces to a simple Bingham model. The HBP model is described in detail in the research [31-33]. In the present study, the tailings' run out flow was regarded as $40 \%$ solid concentration homogeneous slurry with the yield stress of $2.5 \mathrm{~Pa}$ and the viscosity of $0.15 \mathrm{~Pa} \cdot \mathrm{s}$.

The fluid density fluctuation is computed by solving the mass conservation as the particle mass keeps constant in the weakly compressible SPH (WCSPH) computing. The continuity equation in SPH is as follows:

$$
\frac{d \rho_{a}}{d t}=\sum_{b} m_{b} v_{a b} \cdot \nabla_{a} W_{a b}
$$

To account for the WCSPH, the Delta-SPH equation proposed by Molteni and Colagrossi [34] was implemented. A diffusive term is introduced to reduce the density fluctuations. The Delta-SPH equation can be written in the following form.

$$
\frac{d \rho_{a}}{d t}=\sum_{b} m_{b} v_{a b} \cdot \nabla_{a} W_{a b}+2 \delta h \sum_{b} m_{b} \overline{c_{a b}} \times\left(\frac{\rho_{a}}{\rho_{b}}-1\right) \frac{1}{r_{a b}^{2}+\eta^{2}} \cdot \nabla_{a} W_{a b}
$$

where $\delta$ is the diffusive coefficient of Delta-SPH.

The open-source SPH solver DualSPHsysics v4.0 [35] (www.dual.sphysics.org) was used in the present study. A series of .xml (EXtensible Markup Language), stl (STereoLithography), and .sh (SHell script) files were compiled to define the material parameters, system configuration, and modelling execution. The basic SPH constants used were based on the suggested values of the 3D simulation cases in Duals physics. The code was then executed on the Graphics Processing Unit (GPU) node 
of a high-performance cluster (HPC) with the NVIDIA Tesla K80 GPU (4992 processor cores with a dual-GPU design, $560 \mathrm{MHz}$, NVIDIA, Santa Clara, CA, USA).

Based on the produced high-resolution UAV SfM DSM result, the real-scale 3D geometry of the research area was constructed after a series of transitions. First, the SfM DSM raster data were imported into the open-source QGIS software (https://qgis.org) and converted to the stl (STereoLithography) format 3D geometry. Thereafter, according to the previous studies, the dam breach widths in most earthen dam breach cases are three times of the breach depths [36], and the ratio of the top breach width to the bottom breach width ranges from 1.06 to 1.74 with an average value of 1.29 [37]. Based on the fact that the elevation of the 29-m-high starter dam was from $+256 \mathrm{~m}$ to $+285 \mathrm{~m}$ and the measured average elevation of the reservoir was $+349.27 \mathrm{~m}$. The TDB width was then set to be $279.81 \mathrm{~m}$ (top breach width) and $216.91 \mathrm{~m}$ (bottom breach width). The TDB mode was simplified to be under extreme conditions where the breach initiates instantaneously at the first step of the simulation. On the basis of available computational capacities, the particle distance was set to $2 \mathrm{~m}$, which eventually generated 936,381 boundary particles and 3,494,863 fluid particles.

\section{Results}

\subsection{UAV SfM Photogrammetry}

The orthophoto and Digital Surface Model (DSM) of the research area are shown in Figures 5 and $6 \mathrm{~b}$. Several factory plants, a water recovery pond, and the G2 highway can be clearly identified on the southwest downstream direction. The TSF waste water delivered by the underdrains is discharged into the $2.2 \times 10^{4} \mathrm{~m}^{2}$ water recovery pond from where it will be pumped back to the processing plant for reuse. The perimeter and area of the TSF are measured to be $2934 \mathrm{~m}$ and $5.11 \times 10^{5} \mathrm{~m}^{2}$, respectively. The average elevations of the dam crest and the reservoir are calculated to be $+353.75 \mathrm{~m}$ and $+349.27 \mathrm{~m}$. The beach width, which indicates the proximity of the supernatant water to the tailings dam and is often regarded as an important surveillance factor can also be clearly observed, as well as the ongoing greening work on the rock-soil embankment in order to control ambient environmental pollution. Meanwhile, the elevation, width, and length of the concrete auxiliary dam crest on the north side are measured to be $+355 \mathrm{~m}, 6 \mathrm{~m}$, and $225 \mathrm{~m}$, respectively. The result ties well with the field survey records. The extracted data can provide evidence for the tailings' discharge planning and operation.

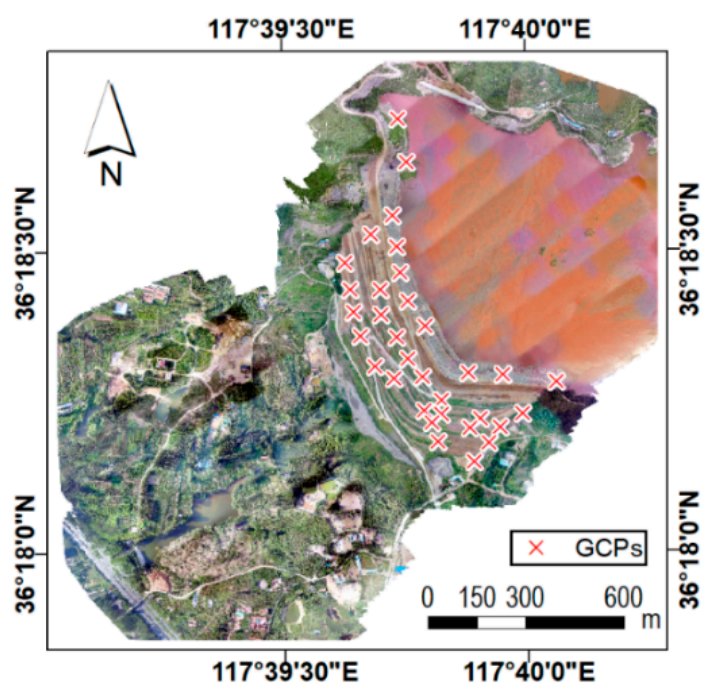

Figure 5. SfM orthophoto and ground control points (GCPs) positions of the research area during the August 2018 survey. 

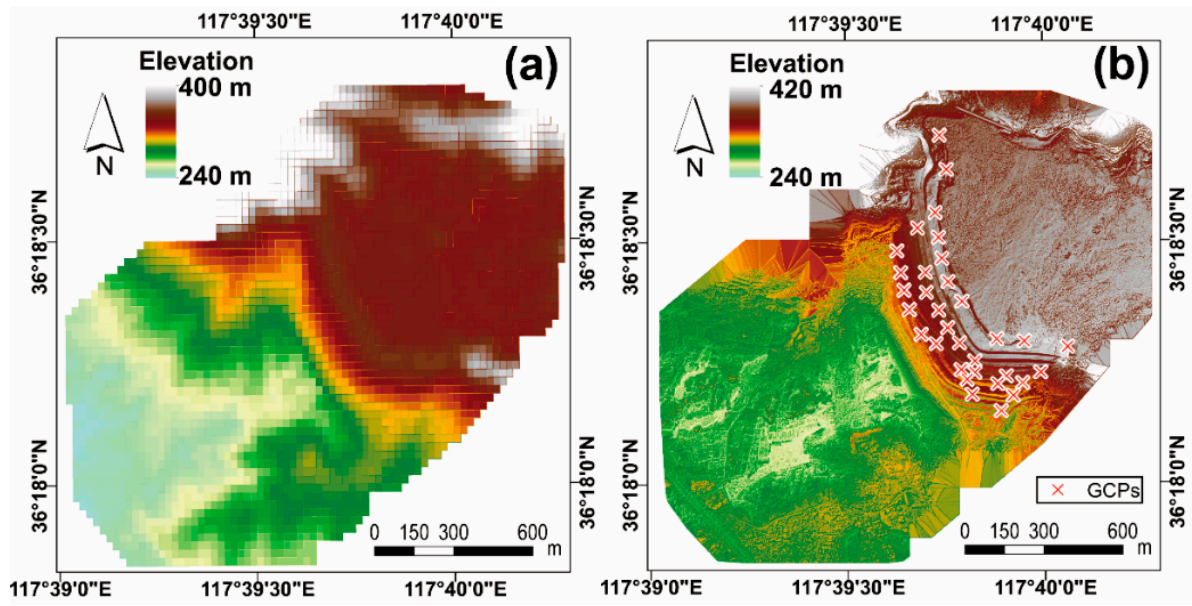

Figure 6. AW3D30 DSM (a) and UAV SfM DSM (b) of the research area.

In addition, the freely available "Advanced Land Observing Satellite (ALOS) World 3D $30 \mathrm{~m}$ mesh" (AW3D30) dataset provided by Japan Aerospace Agency (JAXA) are extracted and illustrated in Figure 6a. The dataset was produced based on the data acquired from 2006 to 2011 by the ALOS satellite and the resolution was 1 arc second (approximately $30 \mathrm{~m}$ ) [38]. A comparative discussion between the AW3D30 and UAV SfM DSMs is presented in Section 4.2.

\subsection{Tailings Dam Breach Overland Flow}

The snapshots of simulated hypothetical dam breach ROOF velocities at 50 s, 150 s, 300 s, and $600 \mathrm{~s}$ are presented in Figure 7. The flow velocity increased greatly at $50 \mathrm{~s}$, as the gravitational potential energy of the tailings flow is swiftly transferred into kinetic energy. In addition, the velocity peak value of $22.6 \mathrm{~m} / \mathrm{s}$ was identified at the dam toe. Thereafter, with the rapid decrease, the TSF capacity and the velocities of ROOF significantly reduced at $150 \mathrm{~s}, 300 \mathrm{~s}$, and $600 \mathrm{~s}$. The velocity peak value had reduced to less than $15 \mathrm{~m} / \mathrm{s}$ at $150 \mathrm{~s}$ and began to impact the downstream water recovery pond. The front flow velocity was lower than $5 \mathrm{~m} / \mathrm{s}$. Thereafter, at $300 \mathrm{~s}$ and $600 \mathrm{~s}$, the flow was spreading at less than $4 \mathrm{~m} / \mathrm{s}$ over the flat area where the water recovery pond and factory plants are located in. At $600 \mathrm{~s}$, a fan-shaped submerged area had formed and the front flow was approaching the G2 highway at less than $2.5 \mathrm{~m} / \mathrm{s}$. The maximum run out distance from the dam crest was measured to be $1224 \mathrm{~m}$ with only $78 \mathrm{~m}$ from the G2 highway. At $600 \mathrm{~s}$, the maximum submerged depth at the low-lying water recovery pond ( $655 \mathrm{~m}$ downstream from the dam crest) was $24 \mathrm{~m}$. Furthermore, the obtained submerged depth of the front flow was $4 \sim 10 \mathrm{~m}$. In addition, the front flow was accumulating at several low-lying spots and several earthworks were built along the highway. Therefore, it can be inferred that the concerned G2 highway was at a safety distance from the Yujiaquan TSF, as the volume and velocity of the approaching front flow had reduced greatly, the road bed altitude was relatively higher, and the emergency response time was sufficient. However, the safety of the factory plants and workers deployed on the downstream flat area should be further considered. 

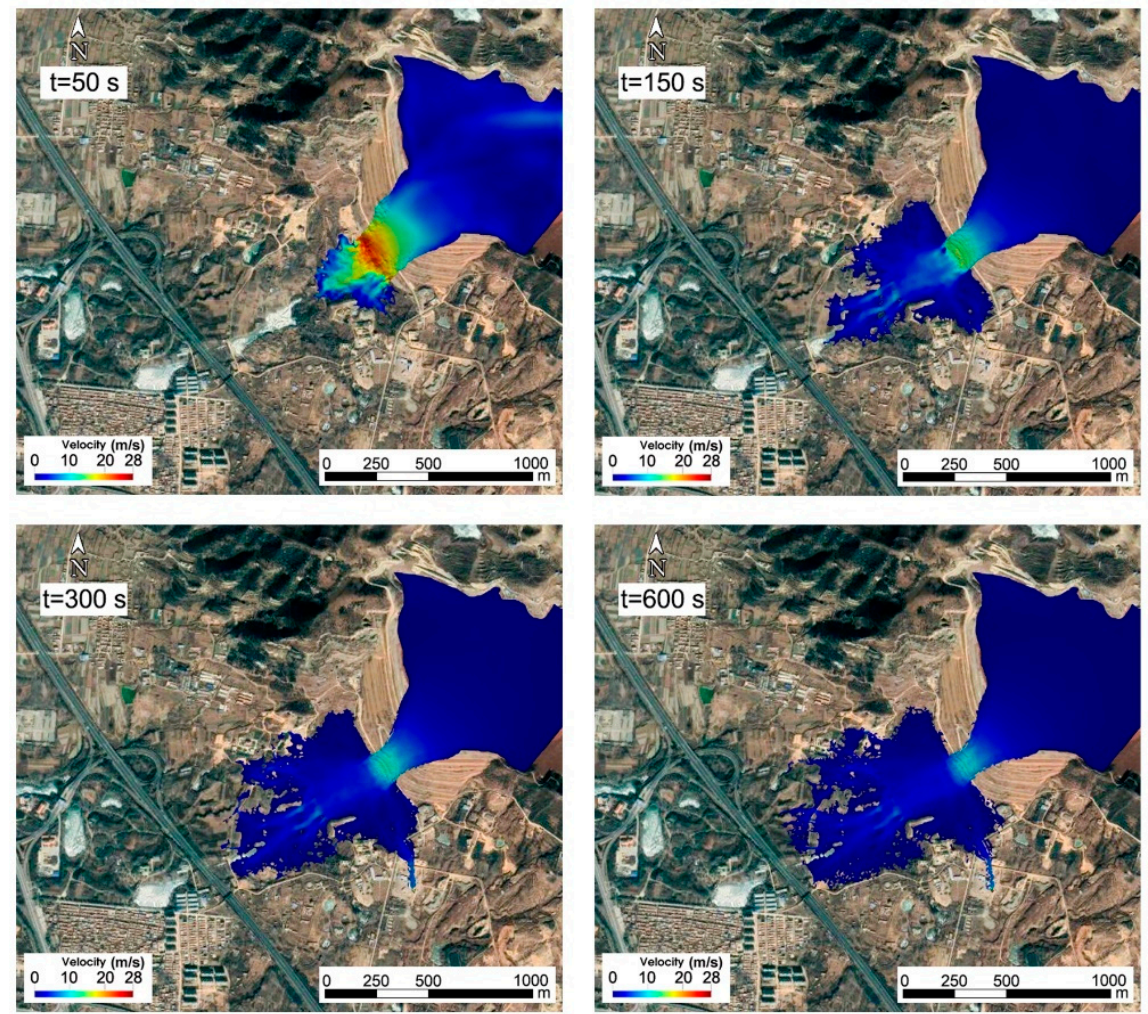

Figure 7. SPH numerical results of Yujiaquan tailings dam breach overland flow routings.

\section{Discussion}

\subsection{Quality of the SFM Photogrammetry Results}

The accuracy and quality of the photogrammetry results are determined by the Ground Sampling Distance (GSD), which means the distance between the center of two consecutive pixels on the ground surface. A lower GSD value indicates a better and more detailed spatial resolution of the results. The GSD is decided by the real focal length $F_{R}(\mathrm{~mm})$, the flight height $H(\mathrm{~m})$, and the covered width of one single image $D_{W}(\mathrm{~m}) . F_{R}(\mathrm{~mm})$ can be calculated by:

$$
F_{R}=\frac{F_{35} \times S_{W}}{k}
$$

where $F_{35}(\mathrm{~mm})$ is the 35-mm equivalent focal length and $S_{W}(\mathrm{~mm})$ is the real sensor width. Furthermore, constant $k$ equals to 34.6 in the $4: 3$ aspect ratio and 36 in the 3:2 aspect ratio. The covered distance on the ground surface by one single image $D_{W}(\mathrm{~m})$ is given by:

$$
D_{W}=\frac{W_{i m} \times G S D}{100}
$$

being $W_{i m}$ is the image width (pixel) and GSD is the expected Ground Sampling Distance (cm/pixel). Given the fact that:

$$
\frac{H}{F_{R}}=\frac{D_{W}}{S_{W}}
$$

Therefore, combining Equations (9)-(11), the GSD can be calculated by:

$$
G S D=\frac{100 \times H \times k}{F_{35} \times W_{i m}}
$$


According to the manufacturer's specifications, the two UAV drones (DJI Phantom 4 Advanced and DJI Phantom 3 Professional) used in the present study are equipped with a 24-mm FC6310 camera and a 20-mm FC300X camera ( $35 \mathrm{~mm}$ equivalent focal length), respectively. The aspect ratio of the FC6310 camera is 3:2 $(5472 \times 3648)$ and the aspect ratio of FC300X camera is 4:3 $(4000 \times 3000)$. Therefore, the GSD from the DJI Phantom 4 Advanced is calculated to be $2.74 \mathrm{~cm} /$ pixel. In the same manner, the GSD from the DJI Phantom 3 Professional is $4.33 \mathrm{~cm} /$ pixel. According to the processing report, the average GSD is $3.8 \mathrm{~cm} /$ pixel.

As Equation (12) suggests, the result quality is highly impacted by the image acquisition parameters and aerial inspection devices. Generally, lower flight heights, longer focal lengths, and higher image widths could decrease the GSD value and produce better results. Focal lengths of $18-24 \mathrm{~mm}$ are frequently used for aerial inspection campaigns because lower flight heights require a wider-angle lens for aerial coverage and image overlap. Moreover, longer focal length lenses are generally heavier, which could shorten the UAV endurance. In addition, proper camera settings, e.g., a low ISO value, a broad aperture, a high shutter speed, RAW image file format, and good weather conditions are also critical to produce better results.

\subsection{Comparison with Spaceborne DSM Product}

The freely available AW3D30 dataset shown in Figure 6a was used for the comparison study. The resolution of the AW3D30 is 1 arc second (approximately $30 \mathrm{~m}$ ), which is much lower than the UAV SfM DSM. Moreover, significant elevation changes of the study area could be observed, as the AW3D30 DSM was produced based on the dataset sampled from 2006 to 2011, 7 12 years earlier than the present UAV field survey. Subsequently, DSMs differences between the AW3D30 and SfM datasets and the contour lines (Figure 8a) were generated by calculating the pixel-by-pixel elevation differences. The elevation differences distribution is plotted and shown in Figure $8 \mathrm{~b}$. The mean and median of the histogram are $15.4 \mathrm{~m}$ and $16 \mathrm{~m}$, respectively. The middle $80 \%$ of the values range between $1 \mathrm{~m}$ and $29 \mathrm{~m}$. It clearly shows that most of the study area, specifically the TSF reservoir surface, the main dam, the G2 highway, and its adjacent area had significantly risen by $10 \mathrm{~m} \sim 40 \mathrm{~m}$ due to the tailings' disposal activities and highway roadbed constructions occurring during the 7 12 years period. In addition, a negative anomaly could be observed on the north-western and northern edges mainly due to the ambient safety maintenance activities during the TSF expansion.
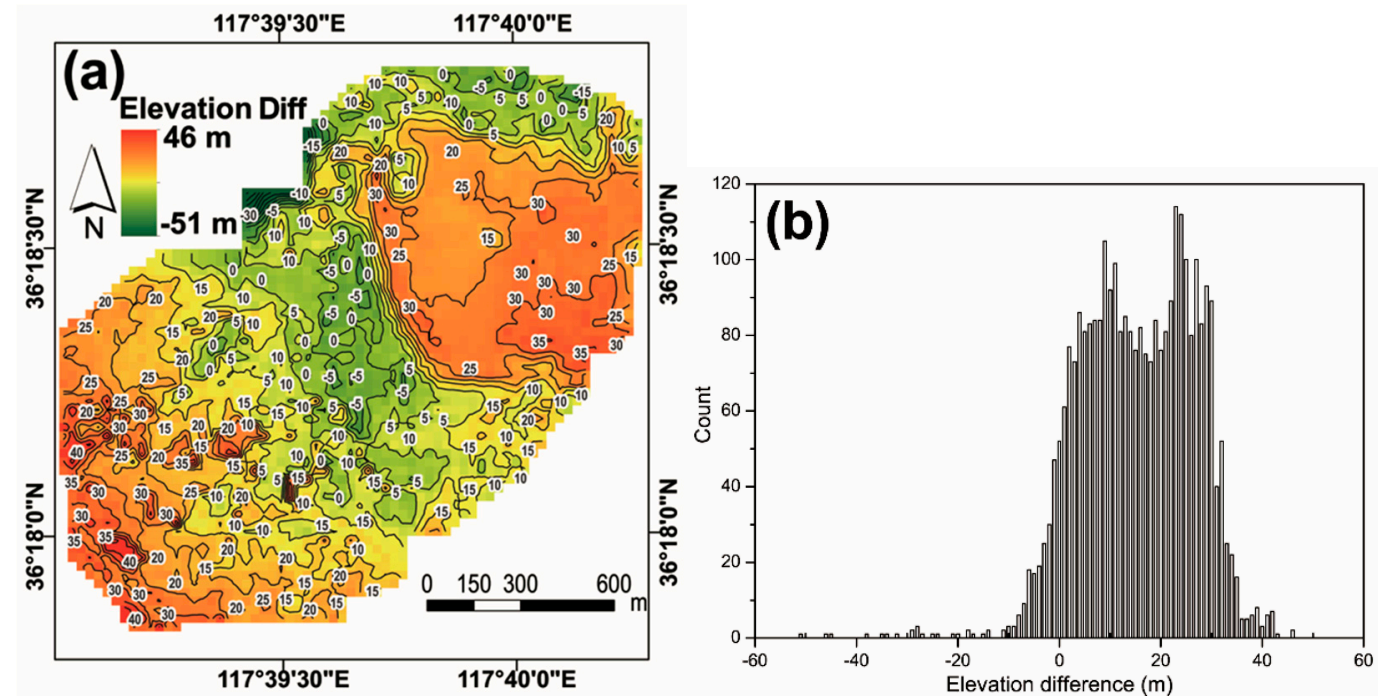

Figure 8. Digital surface models (DSMs) elevation differences (a) and distribution (b) between the SfM DSM and the AW3D30 DSM. 


\subsection{Discussion of the SPH Numerical Results}

As presented in Section 3.2, the hypothetical tailings dam breach ROOF on the downstream complex terrain was simulated using UAV photogrammetry and an SPH numerical method. The concerned G2 highway was considered to be at a safety distance from the TSF due to the accumulation of the front flow at several low-lying spots and the blocking of both the surrounding earthworks and the water recovery ponds near the dam toe. At $600 \mathrm{~s}$, both the front flow velocity and the ROOF submerged depth approaching the G2 highway significantly reduced. In the engineering practice aspect of the TSF disaster prevention and mitigation, the retaining dam or diversion gully built on the path of ROOF is important to minimize the consequences. Therefore, the simulation of hypothetical tailings dam breach ROOF can provide evidence for designing such prevention and mitigation structures. On the other hand, it can be seen that the ROOF routings and submerged area were greatly influenced by the downstream terrain as its gradient variations. In our previous study [16], the procedure of integrating spaceborne remote sensing DSM (approximately $30 \mathrm{~m} * 30 \mathrm{~m}$ resolution) and the SPH method was introduced to predict tailings dam breach routings over downstream terrain. In the present study, the precise and fine timeliness terrain represented by the UAV photogrammetry generated high-resolution DSM is then closer to the real terrain and expected to produce more reliable ROOF simulation results.

Since the amount of disposal tailings will continue to grow for the foreseeable future, and major tailings dam breach accidents are frequently occurring since the 21st century, TSF safety still ranks as the major concern in contemporary mining [16]. Taking China as an example, despite the ongoing efforts of underground tailings backfill mining and utilization actions, the annual tailings' disposal amount is still more than 1.5 billion tons. The documented TSF amount is up to 8869 and among them 1425 were designated as the high-risk TSF, which locate within only $1 \mathrm{~km}$ upstream of communities, industrial plants, or other important facilities. The prediction of tailings dam breach ROOF is then of great significance for the stakeholders and administrators to implement better emergency response plans (such as efficient evacuation routes, rational deployments of emergency shelters and rescue equipment, important facilities protection measures, etc.).

\subsection{Significance of the Study}

Numerical simulation with the advantages of flexible settings, reasonable costs, and high efficiency can be the ideal method for the risk assessment of the devastating tailings dam breach accidents. In order to solve the numerical difficulties when modelling large deformation problems using traditional grid methods, the advanced mesh-free SPH method was used in this study. The proposed multidisciplinary procedure was proven effective by a hypothetical tailings dam breach case study in Shandong Province, China. The proposed procedure is then recommended for the risk assessment of the high-risk TSFs.

In addition, UAV SfM photogrammetry is deemed to be a reliable topographic survey technique and has been widely used in the surveillance of heritage, landslides, infrastructure engineering, and so on. In the present study, the reproduced orthophoto and DSM results of Yujiaquan TSF showed significant accuracy and resolution. Moreover, compared with the spaceborne DSM data, the UAV photogrammetry results have the advantages of great timeliness, a repeatable process, flexible schedule, and reasonable costs. It can be inferred that the multi-temporal UAV photogrammetry dataset could provide strong support for the TSF operation during its whole life cycle of site planning, tailings depositing, capacity expansions, site closure, greening, and reclamation.

\section{Conclusions and Future Work}

Over the past decade, catastrophic tailings dam breach accidents highlighted the importance of TSF risk assessment and emergency management. This paper presents a novel multidisciplinary procedure of using UAV photogrammetry and SPH numerical method to determine the run out 
overland flow of a hypothetical TDB. A case study of a hypothetical tailings dam breach in Yujiaquan TSF, Shandong Province, China was then carried out. Some key conclusions are:

1. UAV photogrammetry is an advanced and powerful surveying technique in terms of great timeliness, repeatable process, high resolution, flexible schedule, and reasonable costs, when compared with spaceborne remote sensing. It has broad application scenarios in the mining industry, especially for the numerous small-scale mining sites worldwide, where professional surveillance equipment and topographical surveys are not affordable.

2. The proposed procedure is presented and successfully applied in a case study in Shandong Province, China. The flow peak velocity of $22.6 \mathrm{~m} / \mathrm{s}$ was identified at its dam toe at $50 \mathrm{~s}$ and a fan-shaped submerged area was formed at $600 \mathrm{~s}$. The safety of the factory plants and workers deployed between the dam toe and the G2 highway was suggested to be primarily concerned.

3. The proposed procedure is recommended for the risk assessment of the TSFs. The foreknowledge of the ROOF key features such as the peak velocity and submerged area is critical for the stakeholders to mitigate possible consequences and ensure that catastrophic accidents will not occur.

On the other hand, despite the applicability of the proposed method, dam breach is regarded as very complex phenomena involving a multitude of physical mechanisms, such as sedimentation, rheological property evolution, and more. The dam breach parameters and flow properties are decided by multiple factors, such as the dam breach causes (overtopping, earthquake, seepage corrosion, etc.), tailings saturation rate, damming method, and materials. In the present study, the implemented rheological properties of the ROOF were simplified as low concentration and homogeneous fluid. In addition, the dam breach width and mode were set according to the empirical formula in previous studies. Moreover, the flow interacting mechanism with downstream attachments also need to be considered in future studies.

Author Contributions: Conceptualization, K.W. and P.Y.; Data curation, C.Y. and L.Z.; Formal analysis, K.W.; Funding acquisition, K.W. and P.Y.; Investigation, K.W., P.Y., C.Y. and L.Z.; Methodology, K.W., G.Y. and C.Y.; Project administration, P.Y.; Software, K.W.; Supervision, G.Y.; Validation, K.W.; Writing-original draft, K.W.; Writing-eview \& editing, P.Y. All authors have read and agreed to the published version of the manuscript.

Funding: The National Key R\&D Program of China (grant number 2017YFC0804600) and National Natural Science Foundation of China (grant number 51774045, 51674150 and 51974051) funded this research.

Acknowledgments: We acknowledge the DualSPHysics team who developed the open-source SPH code and the anonymous reviewers that contributed to the improvement of the manuscript.

Conflicts of Interest: The authors declare no conflict of interest.

\section{References}

1. Lottermoser, B.G. Mine Wastes: Characterization, Treatment and Environmental Impacts, 3rd ed.; Springer: Berlin/Heidelberg, Germany, 2010; 400 p.

2. Azam, S.; Li, Q. Tailings dam failures: A review of the last one hundred years. Geotech. News 2010, $28,50-54$.

3. ICOLD; UNEP. Tailings Dams-Risk of Dangerous Occurrences, Lessons Learnt From Practical Experiences (Bulletin 121); International Commission on Large Dams: Paris, France, 2001.

4. WISE Uranium Project. Chronology of Major Tailings Dam Failures (From 1960). Available online: https://www.wise-uranium.org/mdaf.html (accessed on 6 April 2020).

5. Bowker, L.N.; Chambers, D.M. The Risk, Public Liability, E Economics of Tailings Storage Facility Failures; Earthworks: Stonington, ME, USA, 2015.

6. Huang, Y.; Dai, Z. Large deformation and failure simulations for geo-disasters using smoothed particle hydrodynamics method. Eng. Geol. 2014, 168, 86-97. [CrossRef]

7. Zang, C.W.; Chen, M.; Zhang, G.C.; Wang, K.; Gu, D.D. Research on the failure process and stability control technology in a deep roadway: Numerical simulation and field test. Energy Sci. Eng. 2020, 8, 2297-2310. [CrossRef] 
8. Lucy, L.B. A numerical approach to the testing of the fission hypothesis. Astron. J. 1977, 82, $1013-1024$. [CrossRef]

9. Gingold, R.A.; Monaghan, J.J. Smoothed particle hydrodynamics: Theory and application to non-spherical stars. Mon. Not. R. Astron. Soc. 1977, 181, 375-389. [CrossRef]

10. Shadloo, M.; Oger, G.; Le Touzé, D. Smoothed particle hydrodynamics method for fluid flows, towards industrial applications: Motivations, current state, and challenges. Comp. Fluids 2016, 136, 11-34. [CrossRef]

11. Huang, Y.; Zhang, W.; Xu, Q.; Xie, P.; Hao, L. Run-out analysis of flow-like landslides triggered by the Ms 8.0 2008 Wenchuan earthquake using smoothed particle hydrodynamics. Landslides 2012, 9, 275-283. [CrossRef]

12. Pastor, M.; Blanc, T.; Haddad, B.; Petrone, S.; Sanchez Morles, M.; Drempetic, V.; Issler, D.; Crosta, G.B.; Cascini, L.; Sorbino, G.; et al. Application of a SPH depth-integrated model to landslide run-out analysis. Landslides 2014, 11, 793-812. [CrossRef]

13. Vacondio, R.; Mignosa, P.; Pagani, S. 3D SPH numerical simulation of the wave generated by the Vajont rockslide. Adv. Water Resour. 2013, 59, 146-156. [CrossRef]

14. Manenti, S.; Wang, D.; Dominguez, J.M.; Li, S.; Amicarelli, A.; Albano, R. SPH Modeling of Water-Related Natural Hazards. Water 2019, 11, 1875. [CrossRef]

15. McDougall, S.; Hungr, O. A model for the analysis of rapid landslide motion across three-dimensional terrain. Can. Geotech. J. 2004, 41, 1084-1097. [CrossRef]

16. Wang, K.; Yang, P.; Hudson-Edwards, K.; Lyu, W.; Yang, C.; Jing, X. Integration of DSM and SPH to Model Tailings Dam Failure Run-Out Slurry Routing Across 3D Real Terrain. Water 2018, 10, 1087. [CrossRef]

17. Pajares, G. Overview and current status of remote sensing applications based on unmanned aerial vehicles (UAVs). Photogramm. Eng. Remote Sens. 2015, 81, 281-329. [CrossRef]

18. Colomina, I.; Molina, P. Unmanned aerial systems for photogrammetry and remote sensing: A review. ISPRS J. Photogramm. Remote Sens. 2014, 92, 79-97. [CrossRef]

19. Peternel, T.; Kumelj, Š.; Oštir, K.; Komac, M. Monitoring the Potoška planina landslide (NW Slovenia) using UAV photogrammetry and tachymetric measurements. Landslides 2016, 14, 395-406. [CrossRef]

20. Gasperini, D.; Allemand, P.; Delacourt, C.; Grandjean, P. Potential and limitation of UAV for monitoring subsidence in municipal landfills. Int. J. Environ. Technol. Manag. 2014, 17, 1-13. [CrossRef]

21. Lucieer, A.; De Jong, S.M.; Turner, D. Mapping landslide displacements using Structure from Motion (SfM) and image correlation of multi-temporal UAV photography. Prog. Phys. Geogr. 2014, 38, 97-116. [CrossRef]

22. Westoby, M.J.; Brasington, J.; Glasser, N.F.; Hambrey, M.J.; Reynolds, J. ‘Structure-from-Motion'photogrammetry: A low-cost, effective tool for geoscience applications. Geomorphology 2012, 179, 300-314. [CrossRef]

23. Rauhala, A.; Tuomela, A.; Davids, C.; Rossi, P.M. UAV Remote Sensing Surveillance of a Mine Tailings Impoundment in Sub-Arctic Conditions. Remote Sens. 2017, 9, 1318. [CrossRef]

24. Barreiro, A.; Dominguez, J.M.; AJ, C.C.; Gonzalez-Jorge, H.; Roca, D.; Gomez-Gesteira, M. Integration of UAV photogrammetry and SPH modelling of fluids to study runoff on real terrains. PLoS ONE 2014, 9, e111031. [CrossRef]

25. Wendland, H. Piecewise polynomial, positive definite and compactly supported radial functions of minimal degree. Adv. Comput. Math. 1995, 4, 389-396. [CrossRef]

26. Monaghan, J.J. Simulating free surface flows with SPH. J. Comput. Phys. 1994, 110, 399-406. [CrossRef]

27. Fundão Tailings Dam Review Panel. Report on the Immediate Causes of the Failure of the Fundão Dam. Available online: http://fundaoinvestigation.com/the-panel-report/ (accessed on 1 October 2017).

28. Jing, X.; Yin, G.; Wei, Z.; Zhang, Q.; Wang, M. Study of tailings dam-break surges with floating slurry in model experiment in different collapse gates. Rock Soil Mech. 2012, 33, 745-752. (In Chinese)

29. Mahdi, A.; Shakibaeinia, A.; Dibike, Y.B. Numerical modelling of oil-sands tailings dam breach runout and overland flow. Sci. Total Environ. 2020, 703, 10. [CrossRef]

30. Yu, D.Y.; Tang, L.Y.; Chen, C.C. Three-dimensional numerical simulation of mud flow from a tailing dam failure across complex terrain. Nat. Hazards Earth Syst. Sci. 2020, 20, 727-741. [CrossRef]

31. Han, Z.; Su, B.; Li, Y.G.; Wang, W.; Wang, W.D.; Huang, J.L.; Chen, G.Q. Numerical simulation of debris-flow behavior based on the SPH method incorporating the Herschel-Bulkley-Papanastasiou rheology model. Eng. Geol. 2019, 255, 26-36. [CrossRef]

32. Papanastasiou, T.C. Flows of Materials with Yield. J. Rheol. 1987, 31, 385. [CrossRef] 
33. Fourtakas, G.; Rogers, B.D. Modelling multi-phase liquid-sediment scour and resuspension induced by rapid flows using Smoothed Particle Hydrodynamics (SPH) accelerated with a Graphics Processing Unit (GPU). Adv. Water Resour. 2016, 92, 186-199. [CrossRef]

34. Molteni, D.; Colagrossi, A. A simple procedure to improve the pressure evaluation in hydrodynamic context using the SPH. Comput. Phys. Commun. 2009, 180, 861-872. [CrossRef]

35. Crespo, A.J.C.; Domínguez, J.M.; Rogers, B.D.; Gómez-Gesteira, M.; Longshaw, S.; Canelas, R.; Vacondio, R.; Barreiro, A.; García-Feal, O. DualSPHysics: Open-source parallel CFD solver based on Smoothed Particle Hydrodynamics (SPH). Comput. Phys. Commun. 2015, 187, 204-216. [CrossRef]

36. Trieste, D.J. Downstream Hazard Classification Guidelines; US Department of the Interior, Bureau of Reclamation: Washington, DC, USA, 1988.

37. Singh, V.P.; Scarlatos, P.D. Analysis of gradual earth-dam failure. J. Hydraul. Eng. 1988, 114, 21-42. [CrossRef]

38. Tadono, T.; Nagai, H.; Ishida, H.; Oda, F.; Naito, S.; Minakawa, K.; Iwamoto, H. Generation of the 30 M-Mesh Global Digital Surface Model by Alos Prism. Int. Arch. Photogramm. Remote Sens. Spatial Inf. Sci. 2016, 41, 157-162. [CrossRef]

(C) 2020 by the authors. Licensee MDPI, Basel, Switzerland. This article is an open access article distributed under the terms and conditions of the Creative Commons Attribution (CC BY) license (http://creativecommons.org/licenses/by/4.0/). 